\title{
Research on Teaching Design and Application of Hybrid Learning in Cloud Class
}

\author{
Zhihua Wen \\ Beijing East Staff University \\ wzhredhair@163.com
}

Keywords: cloud classroom; hybrid learning; adult education

\begin{abstract}
From the perspective of promoting " truly effective learning", this paper combines the open advantages of cloud class with the optimization of teaching elements in hybrid learning to design teaching for learning environment, learning resources and learning tasks. This paper probes into the practical process of developing the hybrid learning under the cloud class in adult colleges and universities, to provide practical guidance for adult education and teaching from the perspective of cloud class.
\end{abstract}

\section{Summary of Hybrid Learning}

Singh \& Reed believes that blended learning is "a learning method that delivers' appropriate' skills to' appropriate' learners at' appropriate' time by applying' appropriate' learning techniques to match' appropriate' learning styles, thus achieving optimal learning results." ${ }^{[2]}$

\section{Teaching design of Hybrid Learning in Cloud Class}

Taking the Basis of Computer Engineering course as a practical carrier, I carry out front-end analysis and design of learning activities, and describe in detail the organization and practical process of carrying out hybrid learning in cloud class.

According to the theory of learning-based instructional design, the implementation process of Basis of Computer Engineering course, a public basic course in adult colleges, is divided into four parts: front-end analysis, learning activity design, teaching implementation and learning effect evaluation. The organization and practical process of carrying out hybrid learning based on cloud platform are described in detail.

\subsection{Front-end analysis}

\subsubsection{Analysis of teaching objectives.}

Cognitive goal, Enable students to understand the basic knowledge of computers and software and hardware systems. Ability target, Familiar with basic computer operations and office software, and can be flexibly applied to realize the cultivation of knowledge acquisition ability and practical ability .Affective goal, Providing mixed learning methods to students so that students can become the leading learners and cultivate self-study awareness. ${ }^{[3]}$ 


\subsubsection{Analysis of students' characteristics.}

The students of the course Basis of Computer Engineering are freshmen in adult colleges and universities. They have a certain foundation, but their level varies greatly. There are also obvious differences in students' interest in computer learning.

\subsection{Learning activity design}

\subsubsection{Design of hybrid learning environment for cloud class}

\subsubsection{Multimedia computer room environment}

The class hours of Basis of Computer Engineering course are 60 hours, of which 40 hours of face-to-face courses are arranged in multimedia classrooms. Face - to - face teaching is to complement and perfect online learning, that is, according to the task of cooperative learning, group class discussions are arranged, and the results of the discussions are elaborated and demonstrated by the group representatives. The feature of face-to-face teaching is to stimulate students' interest in learning and enthusiasm for discussion through classroom activities, and to embody the adult learning concept of "learning with participation".

\subsubsection{Baihui cloud platform learning environment}

Baihui cloud platform is the world's largest online software operator zoho cloud platform that provides more than 20 kinds of services such as CRM and online office platform to Chinese enterprises. Baihui's various cloud-based tools developed for enterprise users have demonstrated good collaboration capabilities and can be fully applied to hybrid learning. This course uses the 100 - meeting wiki, the 100 - meeting document, the 100 - meeting chat and the 100 - meeting forum as its main tools, and uses the 100 - meeting online office, the 100 - meeting calendar, and the 100 meeting notes as its auxiliary tools to build a bridge between teachers and students that is free of time and space restrictions, can communicate and solve problems at any time, and provides a cloud platform for interaction and collaboration for learning activities.

\subsubsection{Hybrid learning resource design in cloud classroom}

Various forms of learning resources are used in this course, such as paper teaching materials, electronic teaching plans, PPT courseware, syllabus, experimental tasks, pictures, videos, network materials, etc. Teachers should not only provide case materials to enable students to imitate, but also provide expanding resources to enable students to carry out innovative design. Not only should resources be provided to students, but also students-centered mixed design and reasonable collocation can lead students to complete knowledge construction from simple to complex, from individual to whole, from concrete to abstract. In this course, the author has also developed several micro-courses suitable for mobile self-study and embedded them into the Baihui wiki. For example, the author has made micro-courses (micro - videos) from the content of "mail merge" which is difficult to understand and master. students can use mobile devices such as mobile phones and tablets to play them repeatedly and learn anytime and anywhere.

\subsubsection{Hybrid learning task design based on cloud platform}

In the course of Basis of Computer Engineering, the author has put the concepts and knowledge points contained in the teaching content into 15 excellent cases. After many years of practice and repeated adjustments, these cases have a large coverage of knowledge points, are practical and 
professional, and have obvious teaching effects. At the same time, try our best to radiate the meaning of an important concept to many cases so that students can fully understand the complexity and relationship of the concept meaning by completing many more complicated cases.

The learning and application of relevant knowledge by learners and the cultivation of learners' comprehensive abilities are the core of blended learning. therefore, the design of learning tasks should pay more attention to problem solving and the design of tasks suitable for collaborative learning. The designed task should be open and cooperative. the process of completing the learning task not only requires students to master basic operation skills and theories, but also hopes that in the process of cooperative learning, students can complete the task together through the joint efforts of the group, and further cultivate the ability of team cooperation and the ability of applying theories to practice. At the same time, the learning task must have results and communicate and judge the results.

\section{Teaching Implementation Stage}

In the process of mixed learning practice, the author set up two learning tasks respectively. From the perspective of learning methods, the teaching implementation stage can be divided into two links: classroom cooperative learning and cloud platform cooperative learning. these two links include small links such as grouping, determining tasks, classroom teaching, autonomous learning, and cooperative learning.

\subsection{Cooperative learning in class}

The classroom cooperative learning activity is mainly a cooperative learning activity with learning tasks as the main line in the classroom. the classroom environment can be a multimedia classroom or computer room, which is mainly composed of seven links, in turn, grouping, determining tasks, classroom learning, task exploration, classroom discussion, achievement exchange and evaluation reflection.

\subsection{Collaborative learning activities in cloud classrooms}

The collaborative learning activity of the Baihui cloud platform is a collaborative learning activity with tasks or projects as the main line on the cloud platform. it is also mainly composed of seven links, namely grouping, determining tasks, making plans, exploring tasks, making works, exchanging results, evaluating and reflecting.

Grouping: Similar to the cooperative learning activities in the classroom, but the grouping tools provided by the cloud platform should be used to complete the grouping. At the same time, teachers also need to enter each group, make adjustments to the group members, roles, and division of labor, and keep records.

Determining tasks: teachers publish collaborative learning tasks on the " hundred societies wiki", clarify the standards of works, provide demonstration cases, provide learning resources such as task book, project planning book, video, PPT, and materials, and upload them to the cloud platform.

Make a plan: after the learners accept the task, they will use the " 100 - meeting chat" or " 100 meeting forum" as a unit to discuss, determine their personal roles, specify the division of tasks, make a task plan, and share it within the group. If it is a project task, you can use "Baihui online office" to make a project planning document and make specific task arrangements on the "Baihui calendar". Teachers need guidance on tasks or project plans.

Mission exploration: The learner learns autonomously according to the micro video provided by the teacher, then reads related resources, and carries out imitation exercises on related cases. 
Students collect data according to their own tasks, build a group database on the "100 - meeting document", and can also discuss problems with members of the small group and teachers through the "100 - meeting chat" or "100 - meeting forum". Teachers carry out supervision and guidance, and learners carry out self - study.

Production of works: After the team members communicate and collaborate with each other through the chat tool on the cloud platform to complete their respective tasks, the team leader will integrate the works and the team members will discuss and rectify the works until all the team members are satisfied. Teachers give timely guidance and encouragement through chat tools and forum tools, and carry out supervision according to the group task plan on the calendar to promote the completion of the project. During this period, members of the small group and teachers can choose any technology or tool to realize synchronous or asynchronous communication and cooperation. For example, in actual teaching, the author used YY voice, QQ class group tools and other auxiliary synchronous online classes.

Results exchange: the group uploaded the works to the Baihui cloud platform, or used "Baihui online office" to produce PPT for display. After being reviewed by teachers and other groups, the group can discuss and exchange the problems encountered in the discussion area. By appreciating the works of others, the group can modify the works again in order to achieve the best results.

Reflection on evaluation: each group evaluates the work through the cloud platform (teachers provide the evaluation scale of self - evaluation, intra-group evaluation and inter-group evaluation) to select the best work, and teachers analyze and evaluate the work; Based on the above evaluation, the teacher summarized the cooperative activities carried out on the cloud platform. Each team should also write a summary of the project activities, reflect on them and summarize the experience of cooperative learning.

\section{Evaluation of Learning Effect}

The teaching evaluation adopts diversified "mixed" methods, i.e. teachers' evaluation is combined with students' self-evaluation and group-to-group mutual evaluation. The formative evaluation of students is combined with the summative evaluation after the course ends. Teachers provide evaluation criteria, self-evaluation criteria and inter-group evaluation criteria for each task work; The evaluation is arranged in different environments. Because there is no restriction on face-to-face evaluation in the classroom, the evaluation on the cloud platform is more free, authentic and credible, and the evaluation effect is better.

\section{References}

[1] Notice of the State Council and the State Council on Printing and Distributing the 13th Five-Year Plan for the Development of National Education Industry [OL]. <http://www.gov.cn/zhengce/content/2017-01/19/content_5161341.htm>

[2] Michael Horn. Blended Learning: Promoting the Educational Revolution with Subversive Innovations [M]. Beijing: Mechanical Industry Press, 2015.

[3] Nie Ai-guo. A Study of the Mixed Teaching Model in Teaching Reform in Colleges and Universities[J].Education and Education Forum, 2016 (38):101-102 